Article

\title{
Numerical Analysis of the Characteristics of Gas Explosion Process in Natural Gas Compartment of Utility Tunnel Using FLACS
}

\author{
Zexu Li ${ }^{1, *}$, Jiansong $\mathrm{Wu}^{1, *}$, Mingyu Liu ${ }^{1}$, Yuntao $\mathrm{Li}^{2}$ and Qiuju Ma ${ }^{1}$ \\ 1 School of Emergency Management and Safety Engineering, China University of Mining \& Technology, \\ Beijing 100083, China; 1610120107@student.cumtb.edu.cn (M.L.); ma200609@126.com (Q.M.) \\ 2 College of safety and Ocean Engineering, China University of Petroleum, Beijing 102249, China; \\ liyt@cup.edu.cn \\ * Correspondence: 18801310633@163.com (Z.L.); jiansongwu@hotmail.com (J.W.)
}

Received: 31 October 2019; Accepted: 1 December 2019; Published: 23 December 2019

\begin{abstract}
With the rapid urbanization in China, directly buried municipal pipelines have been gradually replaced by urban utility tunnels due to a serious shortage of urban underground spaces and weak disaster prevention of traditional municipal pipelines. The urban utility tunnels normally contain electricity pipelines, natural gas pipelines, heat pipelines, sewer pipelines, etc. If a natural gas pipeline leaks, a fire and explosion might occur and lead to serious consequences. In this study, the characteristics of gas explosion in a natural gas compartment of urban utility tunnel are investigated based on FLACS (Flame Acceleration Simulator) simulations. The results revealed that the flame profile undergoes two unstable flame stages. When the ignition position is set at the middle area $(100.25,1.2,1.4 \mathrm{~m})$ of the $200 \mathrm{~m}$-long natural gas compartment, the maximum overpressure of the gas explosion in the $200 \mathrm{~m}$-long natural gas compartment is $25.17 \mathrm{bar}$, which is the largest maximum overpressure under all gas explosion simulation setups. It is also found that the length of the natural gas compartment and different ignition positions have slight effects on the maximum overpressure. This study could provide technical support for structural strength design and division of the fireproofing area of the natural gas compartment in the utility tunnel, which is of great significance to improve urban safety during sustainable development.
\end{abstract}

Keywords: natural gas compartment; gas explosion; overpressure; FLACS; numerical analysis

\section{Introduction}

With the rapid urbanization in China in recent years, the urban population is significantly increasing. To meet the daily needs of the city citizens, the number of urban underground municipal pipelines continues to increase. This leads to a series of problems, such as a serious shortage of urban underground space, increasing difficulty in maintenance and management of municipal pipelines and weak disaster resistance of municipal pipelines, which restricts the sustainable development of the city. In order to solve these problems, urban utility tunnels have been promoted by the government and become an important underground facility for solving the layout of various pipelines in the city. According to recent statistics, the new construction mileage of utility tunnels has been more than $2000 \mathrm{~km}$ since 2016 [1], and some urban utility tunnels have come into service. Urban utility tunnels are underground structures and ancillary facilities with a feeding port, intake shaft, outtake shaft, entrance for persons, ventilation, and monitor, which can hold two or more urban engineering pipelines (electricity pipelines, telecommunicate pipelines, heat pipelines, sewer pipelines, etc.). The common constructions of urban utility tunnels include a natural gas compartment, comprehensive compartment, high voltage compartment, and drainage compartment, as shown in Figure 1. Urban utility tunnels 
can make better use of the urban underground spaces, avoided repeated excavations and enhanced pipeline disaster resistance, which helps to create a good city environment during urbanization.

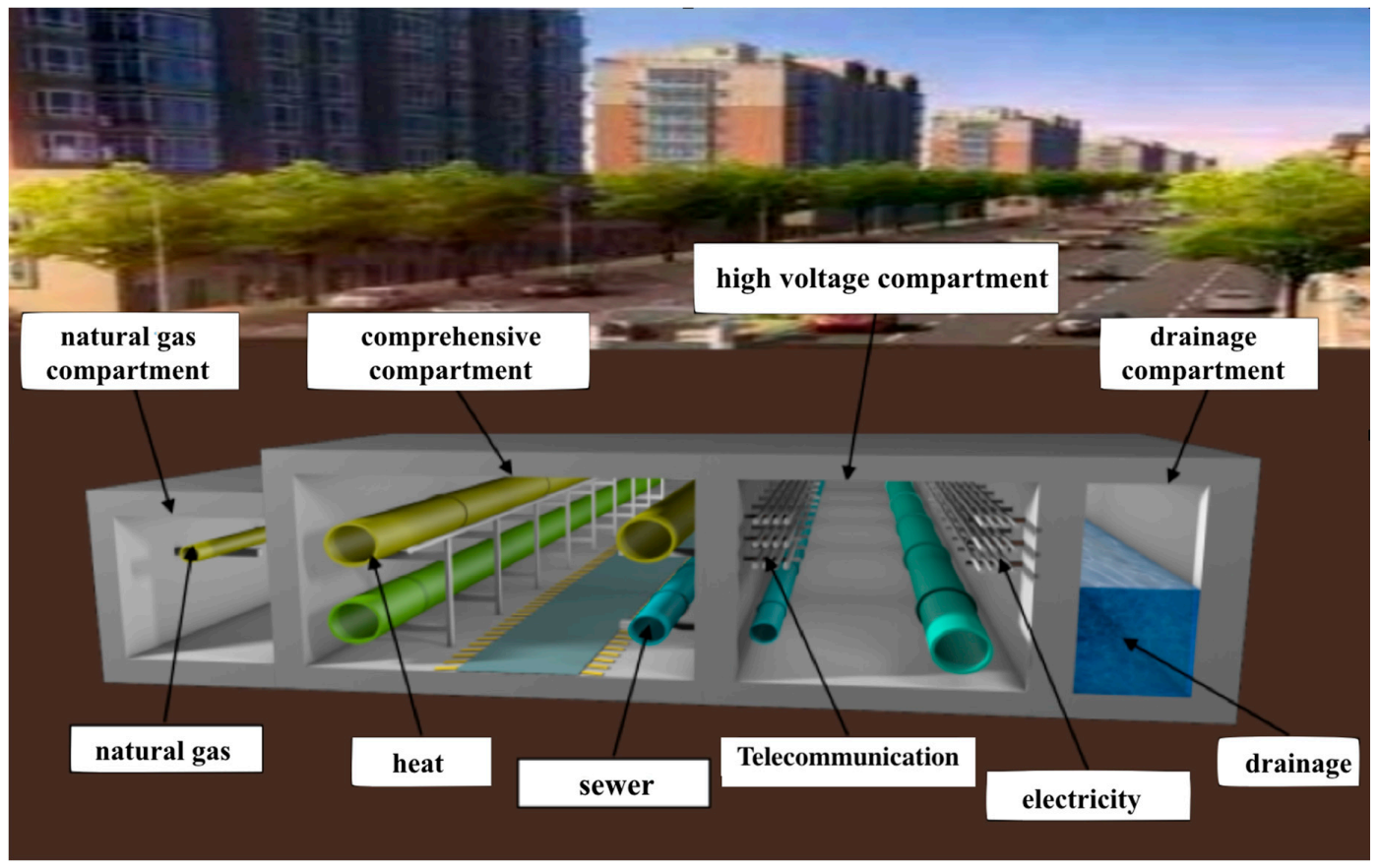

Figure 1. The internal structure of an urban underground utility tunnel.

The urban utility tunnels set multiple pipelines in one tunnel, which could lead to the concentration of multiple hazards (electricity, sewage, high-pressure heat, gas, etc.). The leakage of a natural gas pipeline in natural gas compartment would result in a hazardous zone where a fire and explosion might occur and lead to serious consequences. Thus, the natural gas compartment is one of the most dangerous compartments in urban utility tunnels. In recent years, a number of natural gas pipeline accidents have occurred, i.e., Kaohsiung gas explosion in 2014 [2], causing serious casualties and property losses.

In the past decade, the research on loss prevention and control of urban utility tunnels mainly focuses on hazard identification and risk assessment. Canto-Perello et al. sorted out the hazards involved in the operation space of urban utility tunnels, including the electricity pipeline, sewer pipeline, heat pipeline, gas pipeline, and so on, proposed corresponding countermeasures, and conducted risk analysis on possible threats to urban utility tunnels through the expert system [3-5]. Chen et al. analyzed the structural response of urban utility tunnels under the action of seismic waves [6,7]. At present, there is little research work on natural gas leakage, combustion, and explosion in urban utility tunnels. Zhang et al. analyzed the fire risk types and characteristics of urban utility tunnels and put forward a high expansion foam system for reducing fire loss [8]. However, for the study on gas pipeline leakage and explosion, many scholars have obtained many achievements through theoretical analysis, experimental research, numerical simulations, and other technical means. However, these research achievements on gas combustion and explosion in tunnels do not take any facilities and dynamic ventilation conditions into consideration. Kundu et al. analyzed and summarized several characteristic processes of methane-air mixture combustion and explosion in pipelines and the effects of obstacles on deflagration and detonation [9]. Ibrahim et al. studied the effect of obstacles on overpressure of deflagration [10]. Li et al. presented the propagation characteristics of premixed gas flame under different blocking rates [11,12]. Gamezo et al. evaluated the effects of obstacles interval on deflagration-to-detonation transition and studied the natural gas detonation characteristics and examined the detonation limit $[13,14]$. Gutiérrez Marcantoni et al. studied the effects of chemical 
models on methane-air detonation by numerical simulation [15]. Nie et al. found out the chemical kinetics of the methane explosion process and its influencing factors [16]. Ajrash et al. studied the combustion and explosion characteristics of mixed fuel in a chamber [17]. Xiao et al. investigated the flame propagation characteristics of hydrogen-air mixture in a duct through experimental technical means [18]. Ma et al. presented the explosion characteristics of a mixture of methane, hydrogen, and air [19-21]. Wang et al. used large eddy simulation to investigate the propagation characteristics of explosion waves in coal mine [22]. Unsteady premixed flame propagation around obstacles was analyzed by large eddy simulation, and it is found that the obstacles have important effects on unsteady flame propagation during the explosion process [23-25]. Obstacles cause the vortices to dictate the flame variation, which leads the initially laminar flame to various turbulent combustion. Therefore, the rate of flame propagation and pressure were intensified [26,27]. In addition, the phenomenon of flame/turbulence is also in the hydrogen/methane explosion process, which presents stronger explosion violence $[28,29]$.

According to the literature review above, the current studies on tunnel gas explosion seldom take into account complex equipment and ventilation conditions. However, natural gas compartment in the utility tunnel is equipped with gas pipelines, fire extinguisher boxes, distribution box, and metal brackets, and there is also dynamic ventilation in the natural gas compartment. The layout of these facilities and dynamic ventilation conditions can have a great impact on the characteristics of overpressure and flame propagation during the gas explosion process. In the past decades, FLACS (Flame Acceleration Simulator) has been a widely used numerical tool for effectively simulating the natural gas explosion process. So, it is feasible to study the explosion process in natural gas compartment by using FLACS. FLACS software is a simulation tool developed based on CFD (computational fluid dynamics) technology, which effectively predicts the overpressure characteristics of gas explosion accidents. Vyazmina et al. researched effects of concentration, obstruction vent area, and ignition position on hydrogen vented explosions, and the simulation results are compared with the recent published experimental results to verify the feasibility of the software and provide suggestions for the application of the engineering model and FLACS [30]. Angers et al. utilized FALCS software to model hydrogen explosion characteristics on a pressure swing adsorption device [31]. Lv et al. studied the maximum explosion overpressure of gas in LNG (Liquefied Natural Gas) storage tank areas by numerical simulations and experiments [32]. Davis used FLACS to study the characteristics of gas explosion in the complicated coal mine roadway [33]. Hansen et al. used FLACS to simulate the gas explosion, and compared the simulation results with the experiment data to prove the software feasibility in predicting the explosions [34,35].

For the study of gas explosion process in the natural gas compartment, in this paper, FLACS is used to simulate the gas explosion process in the natural gas compartment. The characteristic parameters in the explosion process (overpressure distribution and flame propagation laws) are analyzed and examined. Furthermore, the characteristics of gas explosion in different natural gas compartments of different lengths are compared to analyze the effects of the division of the fireproofing area. By changing the ignition positions in the same natural gas compartment, gas explosion overpressure characteristics caused by different ignition points were analyzed. The results could provide technical support for structural strength and safety design of the urban utility tunnel in China.

\section{Methodology}

\subsection{FLACS-Explode}

FLACS software is a simulation tool developed based on CFD (computational fluid dynamics) technology, which has been widely applied in gas explosion, powder explosion, LNG (liquefied natural gas) overflow, dangerous gas leakage and diffusion, and so on, and it has been also recognized by authoritative international standards [36]. In the field of gas explosion safety analysis, simulation results of FLACS software are demonstrated with good agreement to experiment data [32,34,37]. 
FLACS software comprises three parts. The first part is called CASD (computer aided scenario design), a preprocessor, that utilizes the input data to define the explosion model for computing simulation. This part contains the computational grid, porosities, geometry model, and scenarios. The second part is called the FLACS simulator, the core solver of the software, which is used to solve the Navier-Stokes equations and add different model modifications. The third part, known as the Flowvis version, a postprocessor is used to present the numeral computing results in a visual way. It can show all tunnels consequence with two dimensions or three dimensions.

In FLACS software, a finite volume method is used to solve the compressible conservation equations on a 3D Cartesian grid. Gas explosion is a very complicated process with chemical reaction. To simplify the computation, the combustion process was calculated by considering only the one-step reaction, the gas that was replaced by methane in the natural gas compartment was settled as the ideal gas heat and inflates, which can be expressed by the continuity equation, momentum equation, energy equation, turbulence kinetic energy equation, turbulence kinetic energy dissipation rate equation, fuel composition equation, and mixture composition equation in FLACS software. It could be generally presented as [37,38]:

$$
\frac{\partial}{\partial \mathrm{t}}(\rho \varphi)+\frac{\partial}{\partial x_{j}}\left(\rho u_{j}\right)=\frac{\partial}{\partial x_{j}}\left(\Gamma_{\varphi} \frac{\partial \varphi}{\partial x_{j}}\right)+S_{\varphi}, \Gamma_{\varphi}=\frac{u_{e f f}}{\sigma_{\varphi}} .
$$

This is the actual form of the conservation equations solved by finite volume-based CFD programs to calculate the flow pattern and associated scalar fields. Where $\varphi$ is the general solver variable (includes mass, momentum, energy, etc.); $\rho$ is the gas density; $x_{j}$ is the integration in the $j$ direction; and $u_{j}$ is the velocity vector in $\mathrm{j}$ direction; $\Gamma_{\varphi}$ is the diffuse number; where the $S_{\varphi}$ is source item; where the $u_{e f f}$ is the effective viscosity; and $\sigma_{\varphi}$ is Prandtl number which is a dimensionless number.

In FLACS software, the k-epsilon model is used to model turbulence in explosion and the beta model is used to model the change of combustion reaction rate, which can be confirmed for the simulation explosion process effectively. Discrete equations are derived by the control volume integral method. Staggered grid technique is used, central difference scheme is used for diffusion term, and mixed difference scheme is used for convection term, local linearization method is used for source term. The SIMPLE (Semi-Implicit Method for Pressure Linked Equations) pressure correction algorithm is applied and extended to the additional source term of the compression work for the enthalpy equation of compressible flow. The special flame acceleration solver is used to solve the explosion shock wave, which can take into account the interaction and influence of the flame with the gas pipeline, fire extinguisher boxes, distribution box, etc., and can directly calculate the gas explosion shock wave $[37,38]$.

\subsection{Scenario Description}

According to the Technical Code for Utility-tunnels Engineering (GB50838-2015) [39], the spacing of fire isolation doors in the natural gas compartment should be less than $200 \mathrm{~m}$ to form the independent fire compartment. Meanwhile, two escape-vent hatches with an internal diameter of less than $1 \mathrm{~m}$ should be set at both ends of each independent fire compartment, one is for incoming wind and the other is for outgoing wind, and the normal ventilation and ventilation frequency of the natural gas compartment should be less than 6 air circulation ratios. In order to study the characteristics of gas overpressure in natural gas compartments of different lengths, the 100, 200, and $300 \mathrm{~m}$-long natural gas compartments were selected in the simulation setups. The leakage scenario was set to model the ventilation condition, the area of the leakage hole was set as $0.785 \mathrm{~m}^{2}$. According to Equation (2), the leakage velocities were $0.8,1.6$, and $2.4 \mathrm{~m} / \mathrm{s}$, respectively:

$$
v=\frac{n \times V}{3600},
$$


where $n$ is air circulation ratios; and $V$ is the volume of natural gas compartment without considering the volume of different devices for simplifying the computing; $v$ presents the wind velocity of the escape-vent hatch.

The geometry of the natural gas compartment was built based on GB50838-2015 [39] and referred to the actual without any scaling. The cylinders and boxes were set in the tunnel for modeling different devices (gas pipeline, fire extinguisher boxes, distribution box, metal brackets, and backup line). The fire extinguisher boxes were modeled as $0.7 \mathrm{~m} \times 0.44 \mathrm{~m} \times 0.21 \mathrm{~m}$ box and set every $20 \mathrm{~m}$. The distribution box was settled every beginning of the fire compartment. The cement support system simulates as the configuration in every $6.6 \mathrm{~m}$. The gas pipeline above the cement support system was $0.25 \mathrm{~m}$ in diameter and the section of backup line were set as $0.11 \mathrm{~m} \times 0.22 \mathrm{~m}$, the length of the gas pipeline and backup line was as long as independent fire compartment in natural gas compartment. All geometries were designed to model real devices with positions and dimensions, as shown in Figure 2.

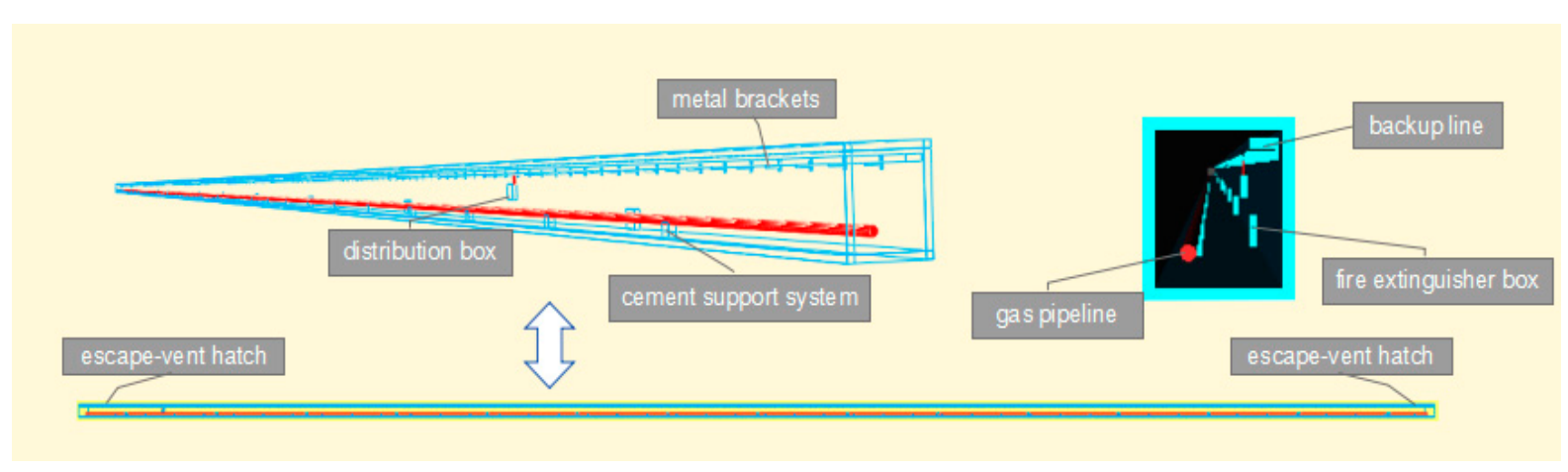

Figure 2. Geometry of natural gas compartment built by CASD.

To model the worse operating condition for gas explosion overpressure in practice, $9.5 \%$ methane and $90.5 \%$ air volume fraction was being filled in the whole natural gas compartment [40], the initial pressure and temperature in the natural gas compartment were 1 bar and $20^{\circ} \mathrm{C}$ to model the normal operating of the natural gas compartment. To ensure numerical stability and with conformity to FLACS validation work [38], value of the Courant-Friedrich-Levy number based on the sound velocity was 0.2 for the explosion simulations, EULER (Euler equations) was used for all boundary conditions in the case where the outflow of the momentum and continuity equations were solved on the boundary.

A simulation volume size was $300 \mathrm{~m} \times 2.4 \mathrm{~m} \times 2.8 \mathrm{~m}, 200 \mathrm{~m} \times 2.4 \mathrm{~m} \times 2.8 \mathrm{~m}, 100 \mathrm{~m} \times 2.4 \mathrm{~m} \times 2.8 \mathrm{~m}$, which were used for three kinds of situations. In order to ensure the accuracy of the calculation results, and not to make the computer difficult to simulate, the number of grids in control volume in natural gas compartments of different lengths is shown in Table 1.

Table 1. The number of grids.

\begin{tabular}{cccc}
\hline $\begin{array}{c}\text { Length of Natural Gas } \\
\text { Compartment (m) }\end{array}$ & X-axis' Grid Number & Y-axis' Grid Number & Z-axis' Grid Number \\
\hline 300 & 600 & 5 & 5 \\
200 & 400 & 5 & 5 \\
100 & 200 & 5 & 5 \\
\hline
\end{tabular}

In FLACS, ignition positions and monitoring points are set according to a grid, not geometry [38], the monitor points and the ignition positions are established in combination with the research purpose and in accordance with FLACS verification. Five monitoring points were set in each case in the natural gas compartment. The coordination position of monitoring points in different length natural gas compartment were listed in Table 2. 
Table 2. The coordination position of the monitoring points in the natural gas compartment.

\begin{tabular}{cccccc}
\hline $\begin{array}{c}\text { Length of Natural Gas } \\
\text { Compartment (m) }\end{array}$ & $\begin{array}{c}\text { Monitor Point } \\
\text { P1 }\end{array}$ & $\begin{array}{c}\text { Monitor Point } \\
\text { P2 }\end{array}$ & $\begin{array}{c}\text { Monitor Point } \\
\text { P3 }\end{array}$ & $\begin{array}{c}\text { Monitor Point } \\
\text { P4 }\end{array}$ & $\begin{array}{c}\text { Monitor Point } \\
\text { P5 }\end{array}$ \\
\hline 100 & $(10.25,1.2,1.4)$ & $(30.25,1.2,1.4)$ & $(50.25,1.2,1.4)$ & $(70.25,1.2,1.4)$ & $(90.25,1.2,1.4)$ \\
200 & $(20.25,1.2,1.4)$ & $(60.25,1.2,1.4)$ & $(100.25,1.2,1.4)$ & $(140.25,1.2,1.4)$ & $(180.25,1.2,1.4)$ \\
300 & $(30.25,1.2,1.4)$ & $(90.25,1.2,1.4)$ & $(150.25,1.2,1.4)$ & $(210.25,1.2,1.4)$ & $(270.25,1.2,1.4)$ \\
\hline
\end{tabular}

To compare and study effects of different ignition positions on methane-air explosion overpressure, these five points of $200 \mathrm{~m}$-long in natural gas compartment were selected for research, as shown in Table 3, the $P$ (pressure) and PROD (means mass fraction of combustion products, which is used to display the flame [38]) are set to the output variable.

Table 3. The coordination position of ignition points in the $200 \mathrm{~m}$-long natural gas compartment.

\begin{tabular}{cccc}
\hline Ignition Point Number & $\mathbf{X}$ axis & Y axis & Z axis \\
\hline 1 & 0.25 & 1.2 & 1.4 \\
2 & 50.25 & 1.2 & 1.4 \\
3 & 100.25 & 1.2 & 1.4 \\
4 & 150.25 & 1.2 & 1.4 \\
5 & 199.75 & 1.2 & 1.4 \\
\hline
\end{tabular}

\section{Results and Discussion}

\subsection{Propagation Characteristics of Gas Explosion in 200 m-Long Natural Gas Compartment}

3.1.1. Propagation Characteristics of Gas Explosion in $200 \mathrm{~m}$-Long Tunnel without Equipment and Ventilation Conditions

Figure 3 shows the development process of flame profile in a tunnel without taking into account any equipment and ventilation conditions. This mainly includes four typical fire profiles, namely spherical flame, finger flame, flat flame, and "tulip" flame. The simulation results are basically consistent with the results of many previous studies [18,41,42].

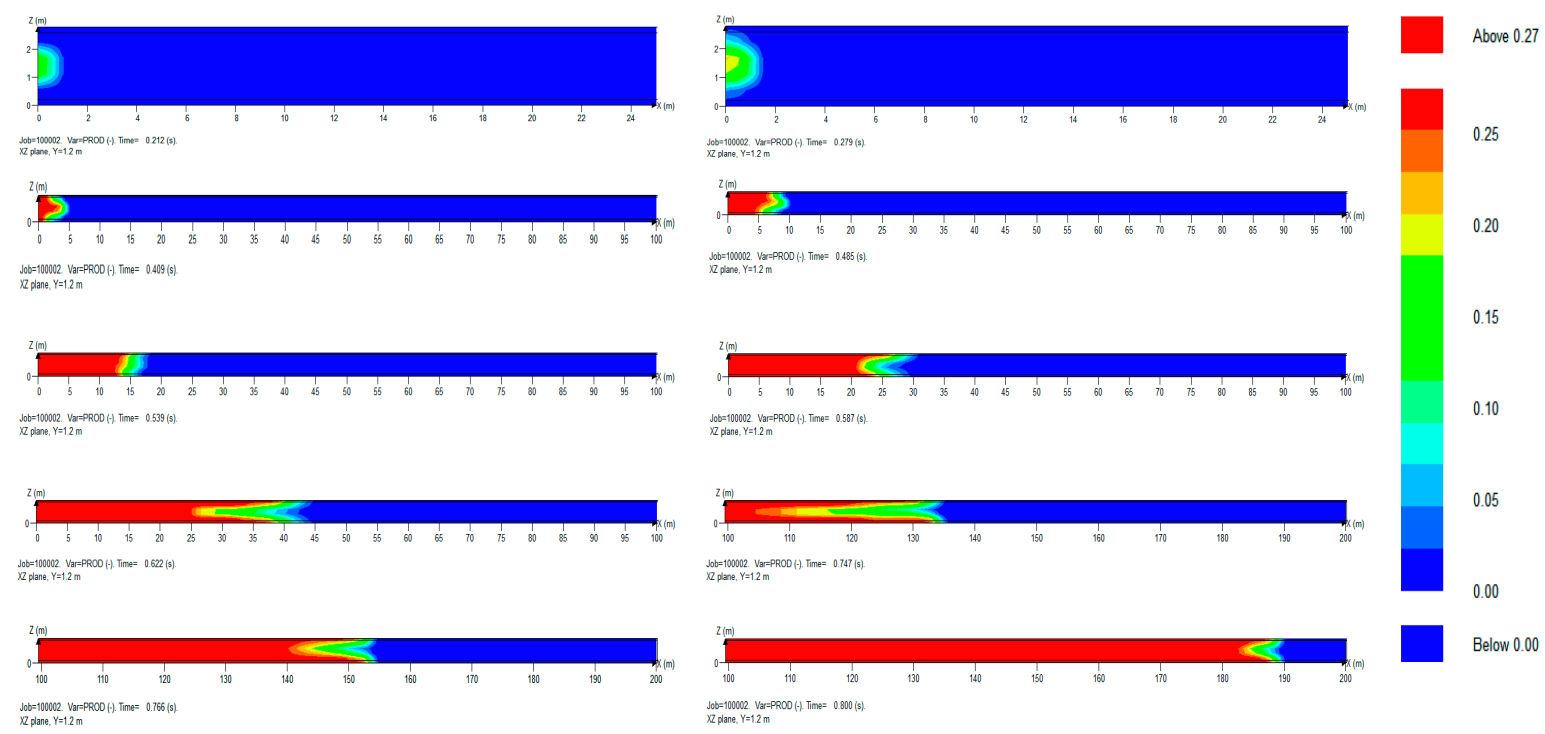

Figure 3. The development process of the flame profile in a tunnel without facilities. 
As shown in Figure 4 and Table 4, the overpressure at monitoring point P5 was the highest, followed by monitor point $\mathrm{p} 4$, monitoring point $\mathrm{P} 2$, monitoring point $\mathrm{P} 1$, and monitoring point $\mathrm{P} 3$, and the maximum overpressure was generated between 0.754 and $0.948 \mathrm{~s}$.

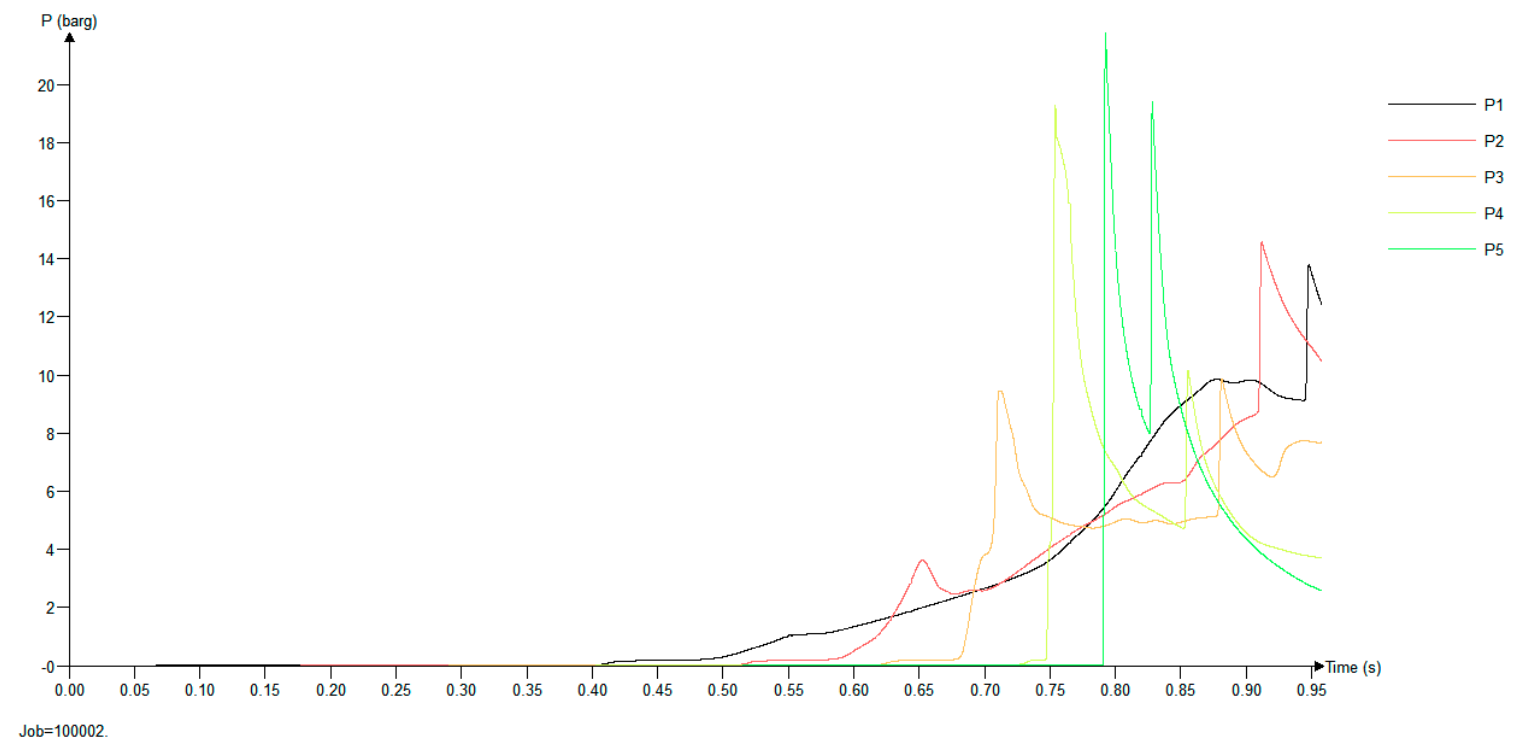

Figure 4. Overpressure changed over time at five monitoring points in a tunnel.

Table 4. The maximum overpressure value and the time at which it is generated at five monitor points.

\begin{tabular}{ccccccc}
\hline $\begin{array}{c}\text { Monitor Point } \\
\text { Number }\end{array}$ & P1 & P2 & P3 & P4 & P5 & $\begin{array}{c}\text { Average } \\
\text { Value }\end{array}$ \\
\hline $\begin{array}{c}\text { Maximum } \\
\text { overpressure (bar) } \\
\text { Time (s) }\end{array}$ & 13.82 & 14.58 & 9.85 & 19.29 & 21.78 & 15.864 \\
\hline
\end{tabular}

3.1.2. Propagation Characteristics of Gas Explosion in a 200 m-Long Natural Gas Compartment of Utility Tunnel

Figure 5 showed the development process of the flame profile in a natural gas compartment with the length of $200 \mathrm{~m}$. It can be seen from Figure 5 that after the methane-air was ignited, in the stage of spherical flame, the development of the flame shape in the natural gas compartment was the same as that in the tunnel without equipment and ventilation conditions. Then, the flame profile gradually became unstable. This was because there are a variety of equipment and facilities in the natural gas compartment, and the corresponding dynamic ventilation conditions were set up, which aggravated the turbulence $[9,11,25,27]$. Then, the flame front profile underwent the stage of flat flame and "tulip flame". Finally, the flame profile became unstable again due to ventilation. 


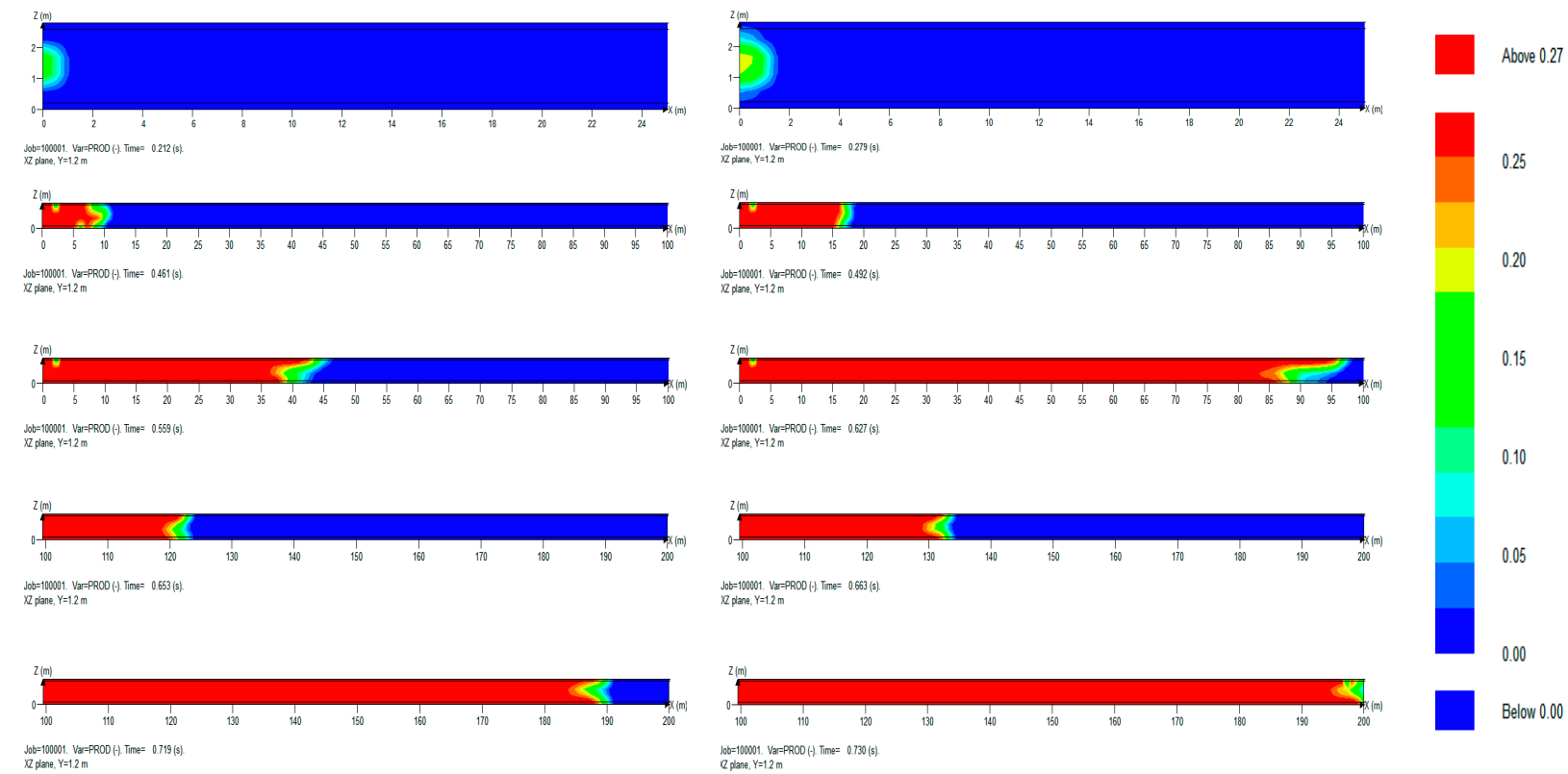

Figure 5. The development process of the flame profile in a natural gas compartment.

As shown in Figure 6 and Table 5, the overpressure at monitoring point P4 was the highest, followed by monitor point $\mathrm{P} 5$, monitor point $\mathrm{P} 3$, monitor point $\mathrm{P} 2$, and monitor point $\mathrm{P} 1$, and the maximum overpressure was generated between 0.640 and $0.844 \mathrm{~s}$.

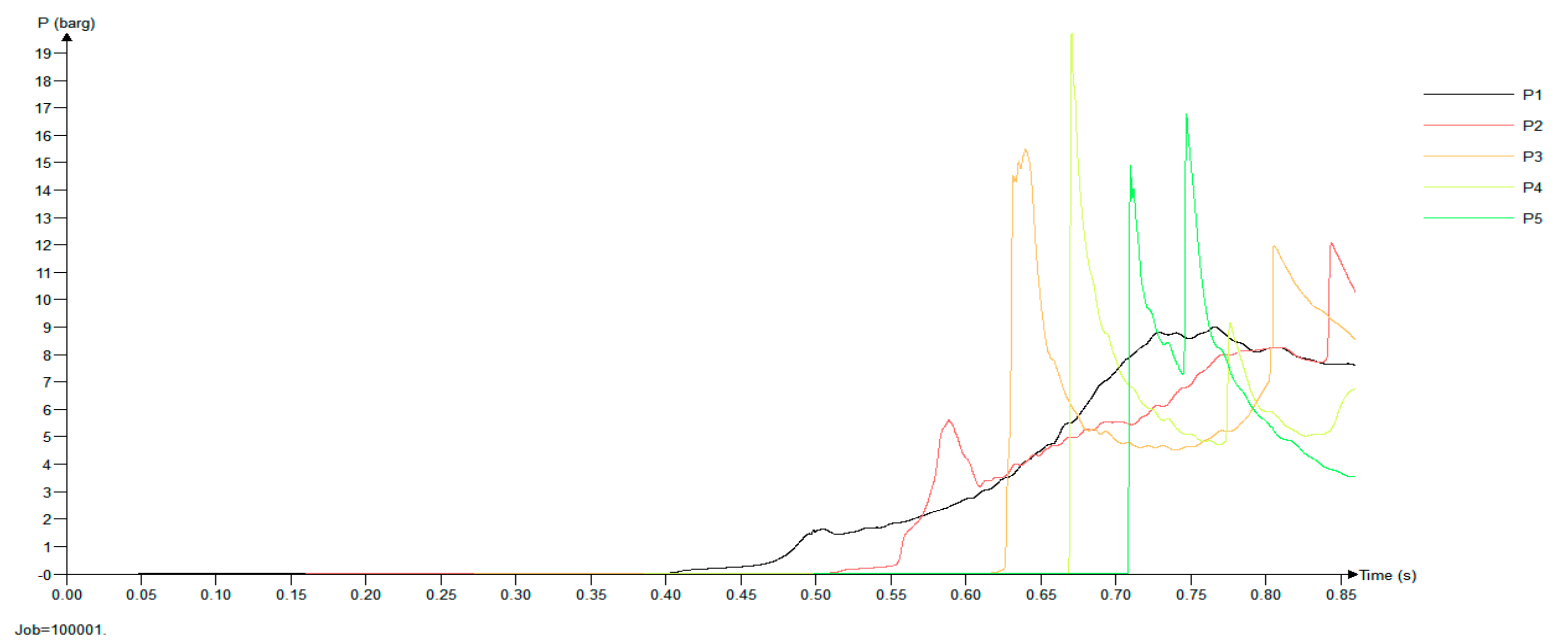

Figure 6. Overpressure changed over time at five monitoring points in a natural gas compartment of the utility tunnel.

Table 5. The maximum overpressure value and the time at which it is generated at five monitoring points.

\begin{tabular}{ccccccc}
\hline $\begin{array}{c}\text { Monitor Point } \\
\text { Number }\end{array}$ & P1 & P2 & P3 & P4 & P5 & $\begin{array}{c}\text { Average } \\
\text { Value }\end{array}$ \\
\hline $\begin{array}{c}\text { Maximum } \\
\text { overpressure (bar) }\end{array}$ & 9.01 & 12.08 & 15.49 & 19.72 & 16.79 & 14.618 \\
Time(s) & 0.766 & 0.844 & 0.640 & 0.670 & 0.747 & 0.7334 \\
\hline
\end{tabular}

It can be seen from Tables 4 and 5 that the average maximum overpressure of the five monitor points in the natural gas compartment was 14.618 bar, while the average maximum overpressure of 
the five monitor points in the enclosure tunnel without equipment and ventilation conditions was 15.864 bar. This was because of the existence of vents in the natural gas compartment, which leads to the attenuation of the pressure wave [43], resulting in the average maximum overpressure of the five monitor points in the natural gas compartment being lower than the average maximum overpressure of the five monitor points in the enclosure tunnel without equipment and ventilation conditions.

The generation time of the maximum overpressure at five monitor points in the natural gas compartment was less than that of the maximum overpressure at five monitor points in the tunnel. This was because after a gas explosion in an enclosed tunnel without equipment and ventilation conditions, the flame from the ignition source expanded to the surrounding premixed gas. A strong chemical reaction occurred at the interface between the unburned gas and the flame front. The heated gas compressed the unburned gas. The pressure waves in the same direction along the flame front were generated. When the pressure wave reached the walls, it changed the original propagation direction, different pressure waves were superimposed on each other to produce maximum overpressure. However, there was a variety of equipment and there is a state of dynamic ventilation in the natural gas compartment, which increased the probability of pressure wave reflection, thus accelerating the occurrence of maximum overpressure [44]. Meanwhile, the equipment (obstacles) and vent conditions cause vortex during the premixed flame propagation along its path in the natural gas compartment. The coupling of flame and vortex results in maximum overpressure and flame deformation [26,27].

\subsection{Gas Explosion Overpressure Characteristics of Different Length of Natural Gas Compartments in Utility Tunnel}

In order to investigate the effects of the length of the natural gas compartment on explosion overpressure, $100 \mathrm{~m}$-long natural gas compartment, $200 \mathrm{~m}$-long natural gas compartment, and $300 \mathrm{~m}$-long natural gas compartment were built and set in the modeling, and the maximum overpressure at the five monitoring points among three length natural gas compartment setups were to estimate worse explosion condition.

The relationship of overpressure changing with time at five monitor points and the maximum overpressure at five monitoring points of three natural gas compartments of different lengths are shown in Figure 7 and Table 6. The average overpressure at the five monitoring points of the $100 \mathrm{~m}$-long natural gas compartment was the highest, followed by the natural gas compartment with the length of $200 \mathrm{~m}$, and the natural gas compartment with the length of $300 \mathrm{~m}$. They are 16.308 bar, 14.618 bar, and 13.942 bar, respectively. However, there are slight differences between the average overpressure at the five monitoring points among three lengths of natural gas compartment simulations setups, which means that the division of the fireproofing area of the natural gas compartment should be based on a comprehensive consideration of finances and safety. 


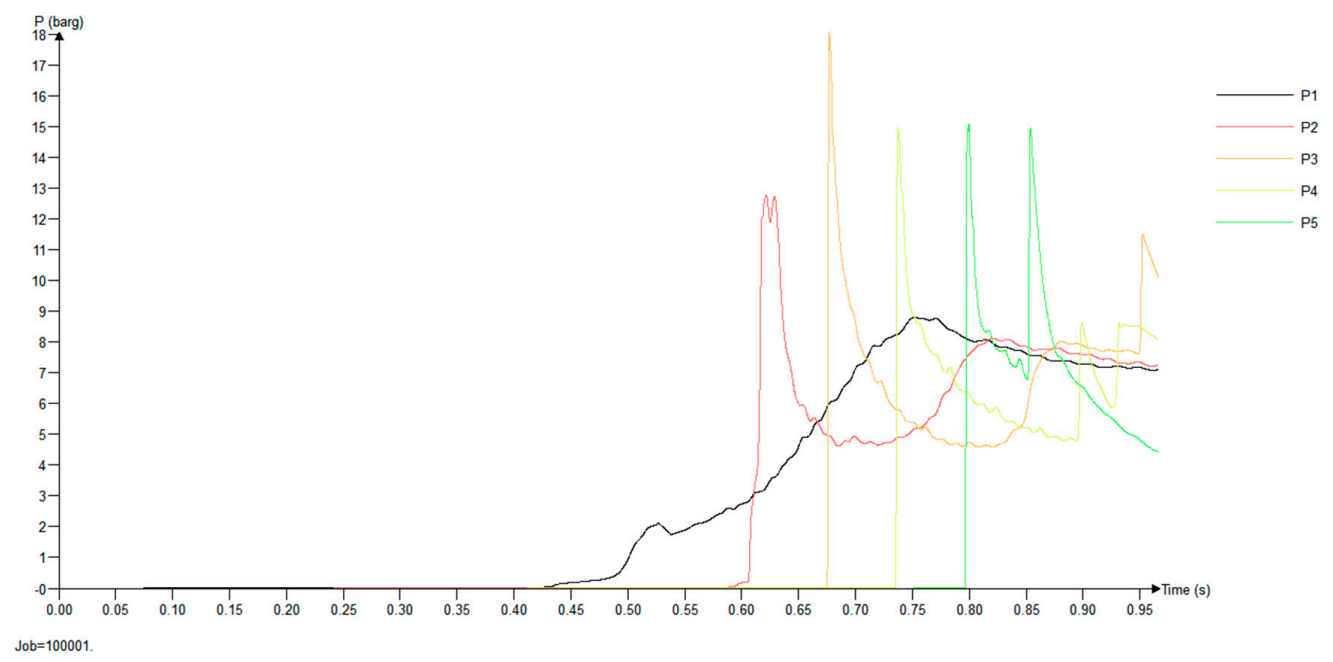

(a)

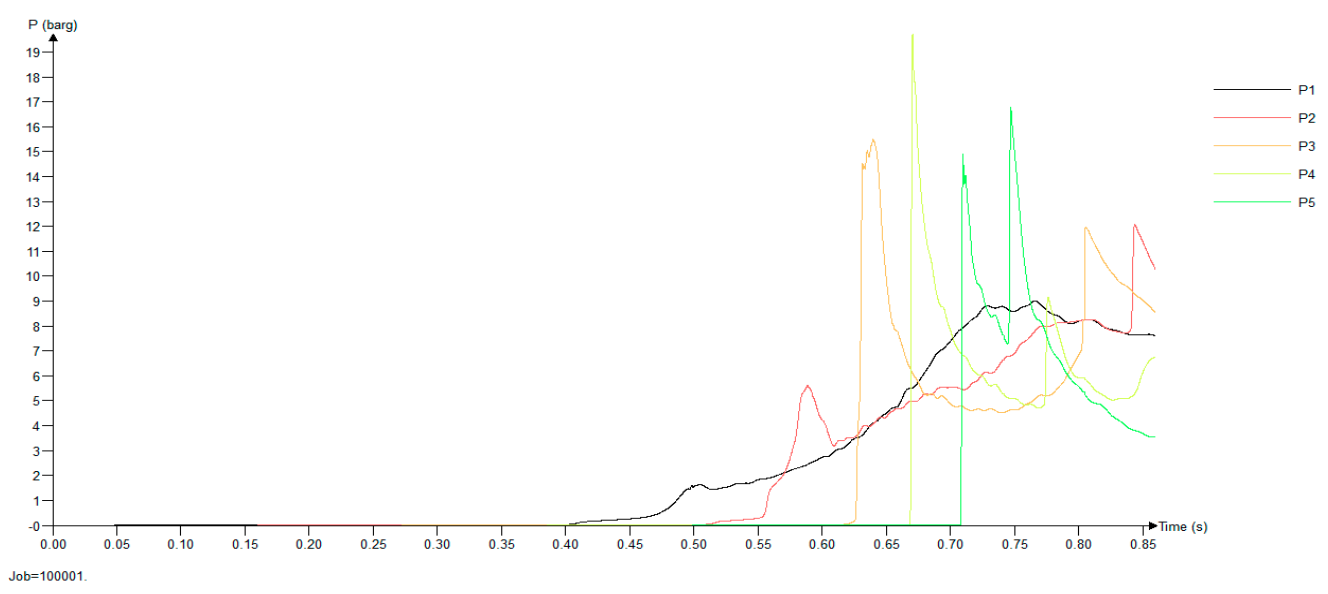

(b)

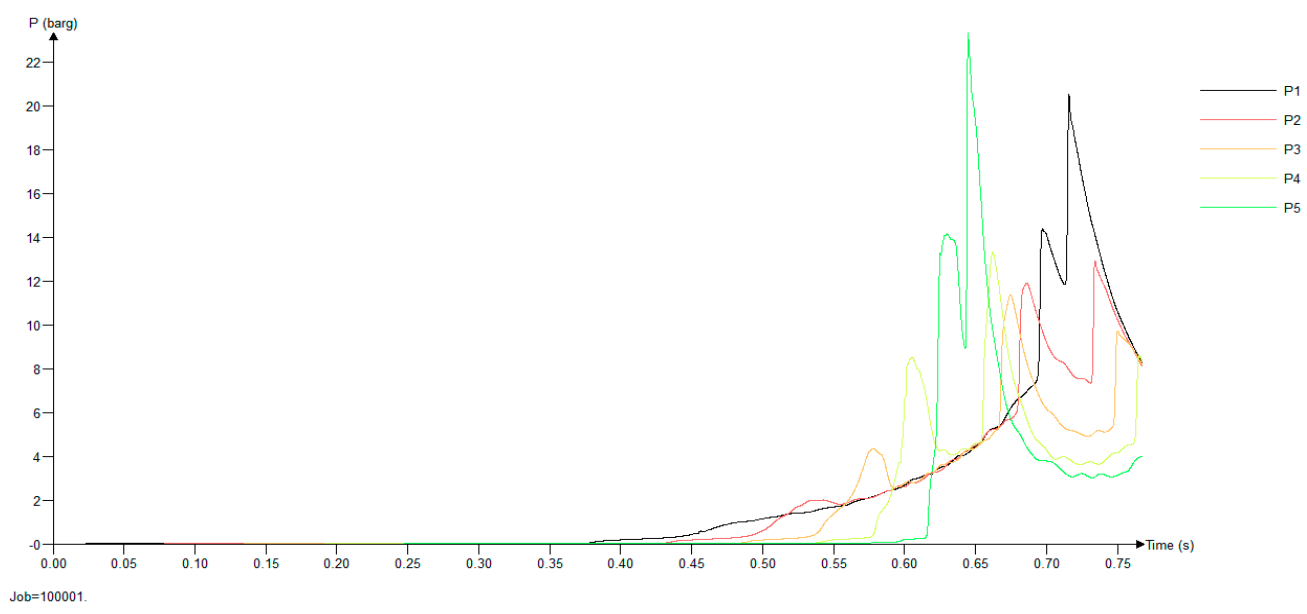

(c)

Figure 7. Overpressure changed over time at five monitoring points in the natural gas compartments of different lengths: (a) 300 m-long natural gas compartment, (b) $200 \mathrm{~m}$-long natural gas compartment, (c) 100 m-long natural gas compartment. 
Table 6. The maximum overpressure at five monitoring points of three different lengths of the natural gas compartment.

\begin{tabular}{ccccccc}
\hline $\begin{array}{c}\text { Maximum } \\
\text { Overpressure (bar) }\end{array}$ & $\begin{array}{c}\text { Monitor } \\
\text { Point P1 }\end{array}$ & $\begin{array}{c}\text { Monitor } \\
\text { Point P2 }\end{array}$ & $\begin{array}{c}\text { Monitor } \\
\text { Point P3 }\end{array}$ & $\begin{array}{c}\text { Monitor } \\
\text { Point P4 }\end{array}$ & $\begin{array}{c}\text { Monitor } \\
\text { Point P5 }\end{array}$ & $\begin{array}{c}\text { Average } \\
\text { Value }\end{array}$ \\
\hline $\begin{array}{c}300 \text { m-long natural } \\
\text { gas compartment }\end{array}$ & 8.81 & 12.77 & 18.08 & 14.96 & 15.09 & 13.942 \\
$\begin{array}{c}\text { 200 m-long natural } \\
\text { gas compartment }\end{array}$ & 9.01 & 12.08 & 15.49 & 19.72 & 16.79 & 14.618 \\
$\begin{array}{c}\text { 100 m-long natural } \\
\text { gas compartment }\end{array}$ & 20.56 & 12.94 & 11.36 & 13.32 & 23.36 & 16.308 \\
\hline
\end{tabular}

3.3. Gas Explosion Overpressure Characteristics with Different Ignition Positions in 200 m-Long Natural Gas Compartment

In order to simulate methane-air explosion overpressure characteristics caused by different ignition points, five ignition position setups in a $200 \mathrm{~m}$-long natural gas compartment were selected as shown in Table 3. The maximum overpressure at each monitoring point were chosen to evaluate the worse explosion case.

From Figure 8 and Table 7, it can be seen that the maximum overpressure generated at monitoring point 3 with the ignition set up in position 3 is the largest, which is 25.17 bar. The average maximum overpressure of five monitoring points with the ignition set in position 3 is the highest, and the average maximum overpressure at monitoring point 3 among five ignition position setups is the highest, which suggests that the center area in the natural gas compartment should receive more attention. However, the average maximum overpressure at five monitoring points in each ignition position setup were in the range of 13.65 to $15.622 \mathrm{bar}$, and the average maximum overpressure with five ignition position setups in each monitoring point were in the range of 13.456 to 15.77 bar, which indicates that the ignition position slightly affects the explosion maximum overpressure.

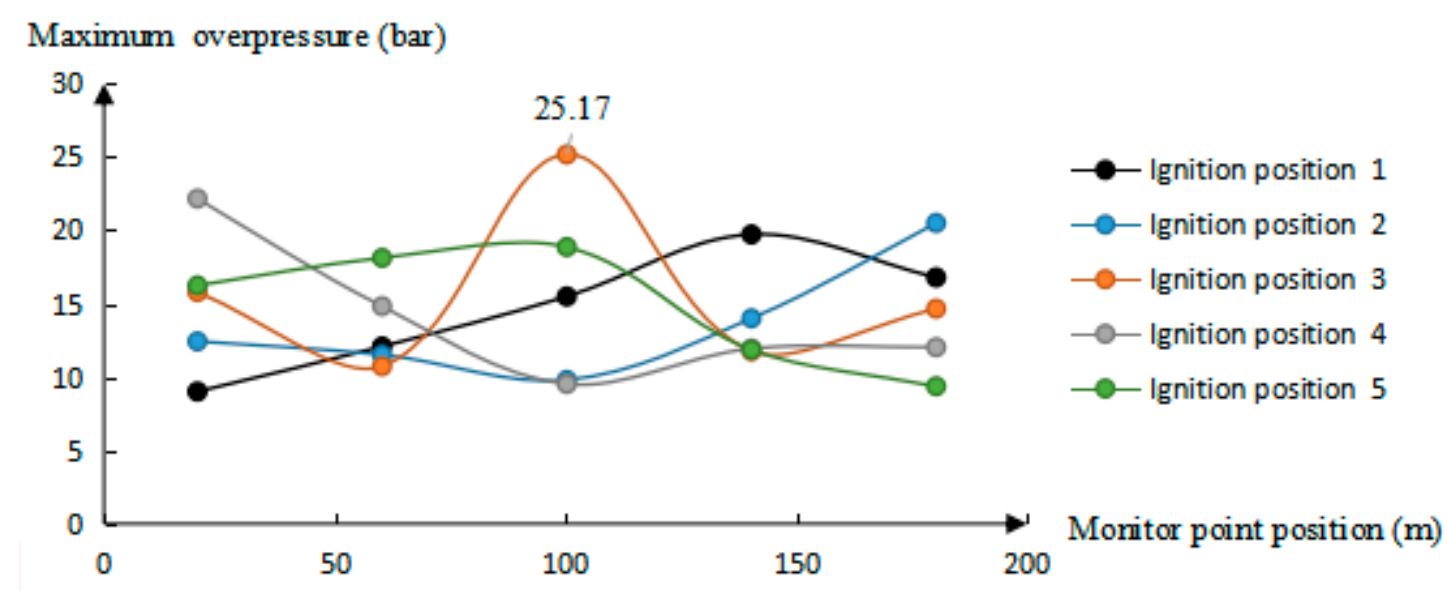

Figure 8. Maximum overpressure changed at different ignition positions in the $200 \mathrm{~m}$-long natural gas compartment.

Table 7. The maximum overpressure at five monitoring points under five different ignition positions.

\begin{tabular}{ccccccc}
\hline $\begin{array}{c}\text { Maximum } \\
\text { Overpressure (bar) }\end{array}$ & $\begin{array}{c}\text { Monitor } \\
\text { Point P1 }\end{array}$ & $\begin{array}{c}\text { Monitor } \\
\text { Point P2 }\end{array}$ & $\begin{array}{c}\text { Monitor } \\
\text { Point P3 }\end{array}$ & $\begin{array}{c}\text { Monitor } \\
\text { Point P4 }\end{array}$ & $\begin{array}{c}\text { Monitor } \\
\text { Point P5 }\end{array}$ & $\begin{array}{c}\text { Average } \\
\text { Value }\end{array}$ \\
\hline Ignition position 1 & 9.01 & 12.08 & 15.49 & 19.72 & 16.79 & 14.618 \\
Ignition position 2 & 12.43 & 11.52 & 9.8 & 14 & 20.5 & 13.65 \\
Ignition position 3 & 15.79 & 10.73 & 25.17 & 11.76 & 14.66 & 15.622 \\
Ignition position 4 & 22.16 & 14.83 & 9.53 & 11.94 & 12.03 & 14.098 \\
Ignition position 5 & 16.24 & 18.12 & 18.86 & 11.86 & 9.73 & 14.962 \\
Average Value & 15.126 & 13.456 & 15.77 & 13.856 & 14.742 & \\
\hline
\end{tabular}




\section{Conclusions}

In this paper, FLACS was used to study the characteristics of the gas explosion process in the natural gas compartment of a utility tunnel. The overpressure distribution of gas explosion and the flame propagation law were investigated. Gas explosion overpressure characteristics of different fire compartments were taken into consideration and the effects of different ignition positions in the $200 \mathrm{~m}$-long natural gas compartment and explosion process were evaluated. The main findings are concluded as follows:

(a) The flame profile undergoes regular changes in the natural gas compartment of a utility tunnel, which mainly includes five stages (spherical flame, unstable flame, flat flame, tulip flame, and unstable flame). When the ignition position is set at the middle area of $200 \mathrm{~m}$-long natural gas compartment $(100.25,1.2,1.4 \mathrm{~m})$, the maximum overpressure of the gas explosion in the $200 \mathrm{~m}$-long natural gas compartment is 25.17 bar, which is the largest maximum overpressure under all gas explosion simulation setups. This information will provide important technical support for structural strength design of the natural gas compartment of the utility tunnel.

(b) The average maximum overpressure in natural gas compartments of different lengths had a small difference, so the division of the fireproofing area in the utility tunnels could consider both financial cost and safety.

(c) The ignition positions do not significantly affect the maximum explosion overpressure. This can provide suggestions for setting loss prevention measures.

In the present work, we mainly focus on analyzing the characteristics of the methane-air explosion propagation in the natural gas compartment. How to suppress gas explosion overpressure and quench flame propagation will be our future research focus.

Author Contributions: Conceptualization, Z.L. and J.W.; Formal analysis, Z.L. and Q.M.; Data curation, Z.L. and J.W.; Funding acquisition, J.W.; Investigation, J.W., Z.L. and Q.M.; Project administration: J.W.; Software, Y.L.; Supervision, J.W.; Writing—original draft, Z.L. and M.L.; Writing—review \& editing, J.W. All authors have read and agreed to the published version of the manuscript.

Funding: This work was supported by the National Key Research and Development Program of China (Grant No.2017YFC0805001), and the opening project of State Key Laboratory of Explosion Science and Technology (Grant No. KFJJ19-09M).

Conflicts of Interest: The authors declare no conflict of interest.

\section{References}

1. Zheng, L.; Yang, C.; Wang, J. Maintenance and Management of Urban Utility Tunnels; China Architecture \& Building Press: Beijing, China, 2017.

2. Chen, C.; Sheen, Y.; Wang, H. Case analysis of catastrophic underground pipeline gas explosion in Taiwan. Eng. Fail. Anal. 2016, 65, 39-47. [CrossRef]

3. Curiel-Esparza, J.; Canto-Perello, J. Risks and potential hazards in utility tunnels for urban areas. Munic. Eng. 2003, 156, 51-56.

4. Curiel-Esparza, J.; Canto-Perello, J. Indoor atmosphere hazard identification in person entry urban utility tunnels. Tunn. Undergr. Space Technol. 2005, 20, 426-434. [CrossRef]

5. Canto-Perello, J.; Curiel-Esparza, J.; Calvo, V. Criticality and threat analysis on utility tunnels for planning security policies of utilities in urban underground space. Expert Syst. Appl. 2013, 40, 4707-4714. [CrossRef]

6. Chen, J.; Jiang, L.; Li, J.; Shi, X. Numerical simulation of shaking table test on utility tunnel under non-uniform earthquake excitation. Tunn. Undergr. Space Technol. 2012, 30, 205-216. [CrossRef]

7. Jiang, L.; Chen, J.; Li, J. Seismic response of underground utility tunnels: Shaking table testing and FEM analysis. Earthq. Eng. Eng. Vib. 2010, 9, 555-567. [CrossRef]

8. Zhang, X.H.; Guan, Y.X.; Fang, Z.; Liao, Y.F. Fire Risk Analysis and Prevention of Urban Comprehensive Pipeline Corridor. Procedia Eng. 2016, 135, 462-467. [CrossRef]

9. Kundu, S.; Zanganeh, J.; Moghtaderi, B. A review on understanding explosions from methane-air mixture. J. Loss Prev. Process Ind. 2016, 40, 507-523. [CrossRef] 
10. Ibrahim, S.S.; Masri, A.R. The effects of obstructions on overpressure resulting from premixed flame deflagration. J. Loss Prev. Process Ind. 2001, 14, 213-221. [CrossRef]

11. Li, Y.; Chen, P.; Bi, M.; Gao, W. Premixed methane/air flame propagating in an obstructed chamber with different BRs and spatial configurations. J. Loss Prev. Process Ind. 2017, 47, 66-71. [CrossRef]

12. Chen, P.; Li, Y.; Huang, F.; Guo, S.; Liu, X. Experimental and LES investigation of premixed methane/air flame propagating in a chamber for three obstacle BR configurations. J. Loss Prev. Process Ind. 2016, 41, 48-54. [CrossRef]

13. Gamezo, V.N.; Ogawa, T.; Oran, E.S. Flame acceleration and DDT in channels with obstacles: Effect of obstacle spacing. Combust. Flame 2008, 155, 302-315. [CrossRef]

14. Gamezo, V.N.; Zipf, R.K., Jr.; Sapko, M.J.; Marchewka, W.P.; Mohamed, K.M.; Oran, E.S.; Kessler, D.A.; Weiss, E.S.; Addis, J.D.; Karnack, F.A.; et al. Detonability of natural gas-air mixtures. Combust. Flame 2012, 159, 870-881. [CrossRef]

15. Gutiérrez Marcantoni, L.F.; Tamagno, J.; Elaskar, S. A numerical study on the impact of chemical modeling on simulating methane-air detonations. Fuel 2019, 240, 289-298. [CrossRef]

16. Nie, B.; Yang, L.; Ge, B.; Wang, J.; Li, X. Chemical kinetic characteristics of methane/air mixture explosion and its affecting factors. J. Loss Prev. Process Ind. 2017, 49, 675-682. [CrossRef]

17. Ajrash, M.J.; Zanganeh, J.; Moghtaderi, B. Methane-coal dust hybrid fuel explosion properties in a large scale cylindrical explosion chamber. J. Loss Prev. Process Ind. 2016, 40, 317-328. [CrossRef]

18. Xiao, H.; Wang, Q.; Shen, X.; An, W.; Duan, Q.; Sun, J. An experimental study of premixed hydrogen/air flame propagation in a partially open duct. Int. J. Hydrogen Energy 2014, 39, 6233-6241. [CrossRef]

19. Ma, Q.; Zhang, Q.; Chen, J.; Huang, Y.; Shi, Y. Effects of hydrogen on combustion characteristics of methane in air. Int. J. Hydrogen Energy 2014, 39, 11291-11298. [CrossRef]

20. Ma, Q.; Zhang, Q.; Pang, L.; Huang, Y.; Chen, J. Effects of hydrogen addition on the confined and vented explosion behavior of methane in air. J. Loss Prev. Process Ind. 2014, 27, 65-73. [CrossRef]

21. Ma, Q.; Zhang, Q.; Pang, L. Hazard effects of high-speed flow from methane-hydrogen premixed explosions. Process Saf. Prog. 2014, 33, 85-93. [CrossRef]

22. Wang, C.; Zhao, Y.; Addai, E.K. Investigation on propagation mechanism of large scale mine gas explosions. J. Loss Prev. Process Ind. 2017, 49, 342-347. [CrossRef]

23. Sarli, V.D.; Benedetto, A.D.; Russo, G. Using large eddy simulation for understanding vented gas explosions in the presence of obstacles. J. Hazard. Mater. 2009, 169, 435-442. [CrossRef] [PubMed]

24. Sarli, V.D.; Benedetto, A.D.; Russo, G. Sub-grid scale combustion models for large eddy simulation of unsteady premixed flame propagation around obstacles. J. Hazard. Mater. 2010, 180, 71-78. [CrossRef] [PubMed]

25. Sarli, V.D.; Benedetto, A.D.; Russo, G.; Jarvis, S.; Long, E.J.; Hargrave, G.K. Large eddy simulation and piv measurements of unsteady premixed flames accelerated by obstacles. Flow Turbul. Combust. 2009, 83, 227-250. [CrossRef]

26. Sarli, V.D.; Benedetto, A.D.; Russo, G. Large eddy simulation of transient premixed flame-vortex interactions in gas explosions. Chem. Eng. Sci. 2012, 71, 539-551. [CrossRef]

27. Sarli, V.D.; Benedetto, A.D. Sensitivity to the presence of the combustion submodel for large eddy simulation of transient premixed flame-Vortex interactions. Ind. Eng. Chem. Res. 2012, 51, 7704-7712. [CrossRef]

28. Sarli, V.D.; Benedetto, A.D. Effects of non-equidiffusion on unsteady propagation of hydrogen-enriched methane/air premixed flames. Int. J. Hydrogen Energy 2013, 38, 7510-7518. [CrossRef]

29. Sarli, V.D.; Benedetto, A.D.; Long, E.J.; Hargrave, G.K. Time-resolved particle image velocimetry of dynamic interactions between hydrogen-enriched methane/air premixed flames and toroidal vortex structures. Int. J. Hydrogen Energy 2012, 37, 16201-16213. [CrossRef]

30. Vyazmina, E.; Jallais, S. Validation and recommendations for FLACS CFD and engineering approaches to model hydrogen vented explosions: Effects of concentration, obstruction vent area and ignition position. Int. J. Hydrogen Energy 2016, 41, 15101-15109. [CrossRef]

31. Angers, B.; Hourri, A.; Benard, P.; Demael, E.; Ruban, S.; Jallais, S. Modeling of hydrogen explosion on a pressure swing adsorption facility. Int. J. Hydrogen Energy 2014, 39, 6210-6221. [CrossRef]

32. Lv, D.; Tan, W.; Liu, L.; Zhu, G.; Peng, L. Research on maximum explosion overpressure in LNG storage tank areas. J. Loss Prev. Process Ind. 2017, 49, 162-170. [CrossRef] 
33. Davis, S.G.; Engel, D.; Van Wingerden, K. Complex explosion development in mines: Case study-2010 upper big branch mine explosion. Process Saf. Prog. 2015, 34, 286-303. [CrossRef]

34. Hansen, O.R.; Johnson, D.M. Improved far-field blast predictions from fast deflagrations, DDTs and detonations of vapour clouds using FLACS CFD. J. Loss Prev. Process Ind. 2015, 35, 293-316. [CrossRef]

35. Hansen, O.R.; Hinze, P.; Engel, D.; Davis, S. Using computational fluid dynamics (CFD) for blast wave predictions. J. Loss Prev. Process Ind. 2010, 23, 885-906. [CrossRef]

36. Available online: https://www.gexcon.com/china/page/flacs-software-overview/en (accessed on 20 December 2019).

37. Luo, Z.; Zhang, Q.; Wang, H.; Cheng, F.; Wang, T.; Deng, J. Numerical simulation of gas explosion in confined space with FLACS. J. China Coal Soc. 2013, 38, 1381-1387.

38. FLACS v9.1 User's Manual; GexCon AS: Bergen, Norway, 2010.

39. Technical Code for Urban Utility Tunnel Engineering; GB 50838-2015; Ministry of Housing and Urban-Rural Development of the People's Republic of China: Beijing, China, 2015.

40. Pekalski, A.A.; Schildberg, H.P.; Smallegange, P.S.; Lemkowitz, S.M.; Zevenbergen, J.F.; Braithwaite, M.; Pasman, H.J. Determination of the Explosion Behaviour of Methane and Propene in Air or Oxygen at Standard and Elevated Conditions. Process Saf. Environ. Prot. Trans. Inst. Chem. Eng. Part B 2005, 83, 421-429. [CrossRef]

41. Eilertsen, J.L.; Rrvik, S.; Foosns, T.; Oye, H.A.; Searby, G. On the “Tulip Flame” Phenomenon. Combust. Flame 1996, 105, 225-238.

42. Kerampran, S.; Desbordes, D.; VEYSSIèRE, B. Study of the Mechanisms of Flame Acceleration in a Tube of Constant Cross Section. Combust. Sci. Technol. 2000, 158, 71-91. [CrossRef]

43. Chao, J.; Bauwens, C.R.; Dorofeev, S.B. An analysis of peak overpressures in vented gaseous explosions. Proc. Combust. Inst. 2011, 33, 2367-2374. [CrossRef]

44. Wang, C.; Ma, T.; Lu, J. Influence of obstacle disturbance in a duct on explosion characteristics of coal gas. Sci. China 2010, 53, 269-278. [CrossRef]

(C) 2019 by the authors. Licensee MDPI, Basel, Switzerland. This article is an open access article distributed under the terms and conditions of the Creative Commons Attribution (CC BY) license (http://creativecommons.org/licenses/by/4.0/). 